\title{
Statistical Model for Gas Turbine Engines Exhaust Emissions
}

DOI:

10.1016/j.trd.2018.01.019

\section{Document Version}

Accepted author manuscript

Link to publication record in Manchester Research Explorer

\section{Citation for published version (APA):}

Filippone, A., \& Bojdo, N. (2018). Statistical Model for Gas Turbine Engines Exhaust Emissions. Transportation Research. Part D: Transport \& Environment: an international journal, 59, 451-463.

https://doi.org/10.1016/j.trd.2018.01.019

\section{Published in:}

Transportation Research. Part D: Transport \& Environment: an international journal

\section{Citing this paper}

Please note that where the full-text provided on Manchester Research Explorer is the Author Accepted Manuscript or Proof version this may differ from the final Published version. If citing, it is advised that you check and use the publisher's definitive version.

\section{General rights}

Copyright and moral rights for the publications made accessible in the Research Explorer are retained by the authors and/or other copyright owners and it is a condition of accessing publications that users recognise and abide by the legal requirements associated with these rights.

\section{Takedown policy}

If you believe that this document breaches copyright please refer to the University of Manchester's Takedown Procedures [http://man.ac.uk/04Y6Bo] or contact uml.scholarlycommunications@manchester.ac.uk providing relevant details, so we can investigate your claim.

\section{OPEN ACCESS}




\title{
Statistical Model for Gas Turbine Engines Exhaust Emissions
}

\author{
Antonio Filipponet*\& Nicholas Bojdo \\ The University of Manchester
}

\begin{abstract}
A statistical analysis has been developed from the ICAO databank to predict aero-engines exhaust emissions during a landing and take-off cycle (LTO). The ICAO databank contains updated emission indices for a vast number of turbojet and turbofan engines only, with thrust ratings greater than $26.7 \mathrm{kN}$. Correlations are developed and proposed for turboprop and turboshaft engines to overcome the difficulty of assessing exhaust emissions from these engines in absence of industry data. LTO emissions are predicted for a turbofan-powered commuter airplane (Embraer E195) using the surrogate model. It is demonstrated that the predictions are closer to the values extracted from the flight data recorder than to the emissions calculated with the ICAO method. Thus, approximate emissions indices applied to actual flight procedures are a better choice that a standard ICAO LTO emission estimate from the databank. The correlations are then applied to the prediction of LTO emissions of a turboprop airplane (Bombardier Q400).
\end{abstract}

${ }^{*}$ School of MACE, George Begg Building, Manchester M13 9PL, UK. † E-mail: a.filippone@manchester.ac.uk. 


\section{Nomenclature}

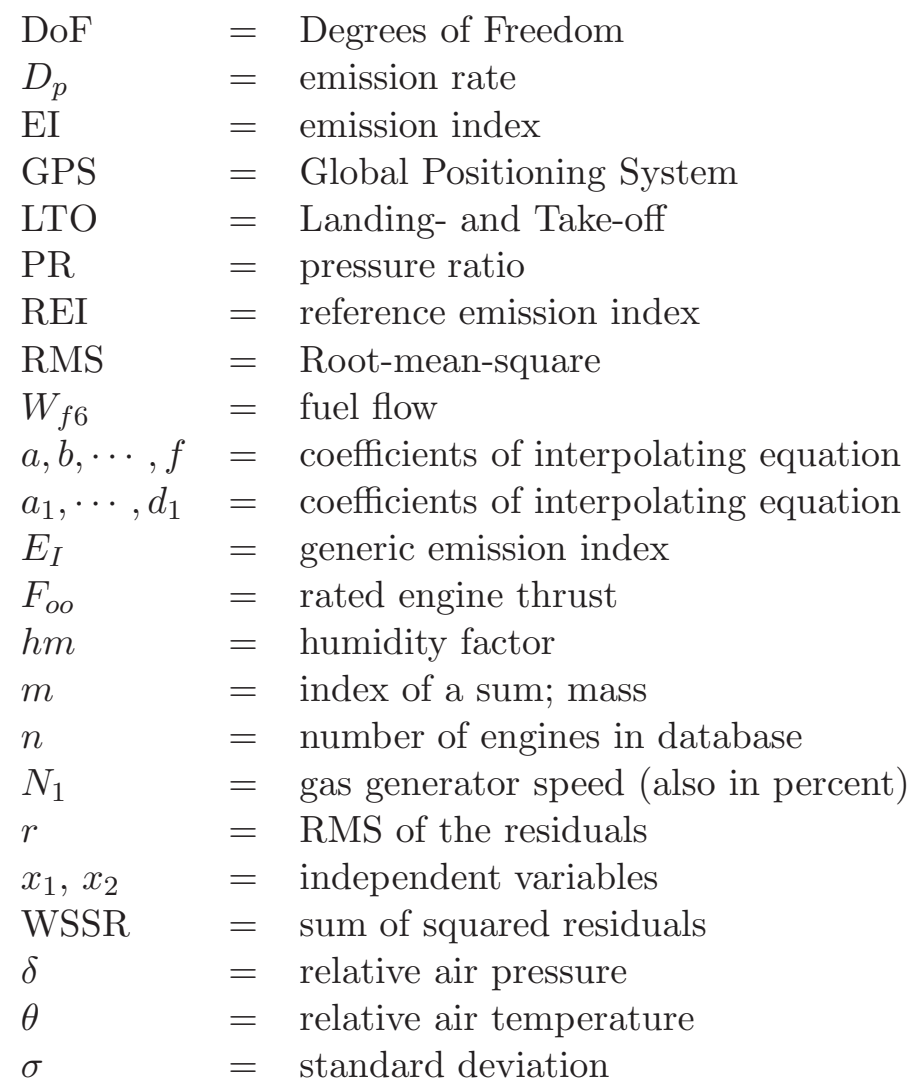

\section{Introduction}

Fossil fuels are the main source of energy for the commercial aviation, and are likely to remain so for the foreseeable future. Therefore, emissions from combustion of aviation fuel will remain a pressing problem at all levels: from engine design, to meeting ever more stringent targets that are agreed at the international level. To predict such emissions, a number of sophisticated multidisciplinary software tools have been developed over the years. These tools deal with emissions forecasting on a local and global scale using aggregate data provided by industry, for example Ref. ${ }^{1}$. Emissions on a global scale have been predicted in a number of projects, and at regular intervals by various organisations, notably NASA ${ }^{2}$, Eurocontrol, the European Commission, and others $^{3}$. A comprehensive review on this matter was published by Masiol \& Harrison ${ }^{4}$ in the context of air quality around airports; these authors included an observation that insufficient information was available to evaluate the variability of emissions at reduced engine thrust.

In any case, most of the emission models rely on the ICAO databank ${ }^{5}$, with the exception of 
$\mathrm{CO}_{2}$ emissions, which are directly related to fuel burn ${ }^{6}$. Exhaust emissions are also calculated using additional industry data, empirical and semi-analytic models, independent models of aircraft performance, aerodynamics and propulsion ${ }^{7}$. Particulate matter is excluded from this database. A number of experimental campaigns in recent years highlighted the complexities of the emissions problem with airborne measurements ${ }^{8 ; 9}$, and measurements at the airfield ${ }^{10}$. Particulate matter, for which considerable research is also available (for example ${ }^{11}$ ), is not considered in the present work.

For engineering analysis, the ICAO is the most extensive source of quantitative information, and is continuously updated with contributions from manufacturers. The database now consists of about 500 gas turbine engine versions, including models no longer in service, no longer in production, or superseded. The data are limited to turbofan engines with thrust ratings above $26.7 \mathrm{kN}$, as there is no obligation to report emissions of smaller engines to the regulator (Notably, military engine data are absent from the database, for example several General Electric turbofans and turbojets: F101, F110, F118).

Other ancillary data that may have technical interest are available, for example the engine test dates. These dates can help identify general trends, such as the increase in overall pressure ratios and by-pass ratios over time.

Using the time-in-mode and the fuel flows indicated by the ICAO, we only obtain notional values of the environmental emissions. These are not real-world occurrences, as pointed out by several authors. Actual emissions depend on a large number of factors, which include the actual ground roll procedures, the gross weight, the deterioration of the engines, atmospheric conditions, derating (or part-thrust) and the fuel consumption. Uncertainty effects in emission indices are evaluated by Lee et al. ${ }^{12}$, who point to uncertainty estimates as large as $55 \%$ for $\mathrm{HC}$ and $26 \%$ for CO. Inaccuracies in fuel consumption have been pointed out by a number of authors, notably Senzig et al. ${ }^{13}$ who proposed a method based on data collected from the Flight-Data Recorder (FDR).

Although the emission data are extremely useful, one must be wary of considering these data applicable to all conditions, since the certification is derived from a limited number of tests (typically, 3 new engines), at specified atmospheric conditions and at a fixed altitude. Thus, there are issues concerning engine deterioration effects, variability of performance data across engines of the same family, etc., as also indicated by measurements published by ${ }^{14}$ for $\mathrm{NO}_{x}$. Caution must be exercised when extrapolating these emissions to a global scale and to a long time frame involving future 
aircraft operations, as it may lead to incorrect conclusions and inappropriate policies.

Deterioration effects can be substantial, as reported in previous research ${ }^{15}$. Luckachko et al. ${ }^{16}$ also illustrated historical trends in engine emissions. Historical data are available within the ICAO database only as a test date (most of the tests were conducted after 1980). A problem with the test date is that within the database it has no clear correlation with actual technology level. Combustor details are important, but are mostly of commercial nature ("reduced emissions", "environmental kit", "phase 3", etc.), and carry no useful information. Yet, there are a few exceptions. For example, the GE low-emission combustor for the GEnx engines is documented by Foust et al. ${ }^{17}$, and named twin annular premixing swirl (TAPS). This technology shows considerable improvements in emissions at some engine modes over prior architecture. The TALON X technology, documented by Pratt \& Whitney ${ }^{18}$, is used in about a dozen certified engines; it can also be mapped against other combustor technologies, as demonstrated later. Recent research into swirl effects in the combustor ${ }^{19}$ shows promising results in reducing emissions, particularly $\mathrm{NO}_{x}$.

Semi-analytical methods have been proposed on the basis of gas turbine test data ${ }^{20}$; it was verified in the course of this work that the correlations proposed do not apply to aero engines. The predictions of these algebraic formulas proposed by Rizk \& Mongia are well above the normal values for aero engines. The semi-analytical model has, in principle, the advantage of taking into account other factors, such as the fuel residence time in the combustor, the evaporation time, and the particle size distribution. Unfortunately, these parameters may only be available in aggregate, not specifically for any engine. Therefore, any higher-order model would fail by virtue of uncertainties in the simulation chain. Other engineering methods exist for the prediction of $\mathrm{NO}_{x}$ from gas turbine combustors $^{21}$. These, as the previous ones, rely on four key parameters in the combustor: entry pressure and temperature, pressure drop and fuel-to-air ratio - data not readily available from the ICAO database or from the manufacturers. Likewise, it is known that maximum combustion temperatures have slowly increased from about $1,800 \mathrm{~K}$ to $2,000 \mathrm{~K}$ in the past 30 years, but data are not published for specific engines.

There are proprietary methods in the industry to estimate exhaust emissions. These methods are not published, not available for research, and are dependent on a larger set of data that is not possible to access for estimates of aviation emissions.

Aside from these caveats, the main motivator of the analysis shown in this paper is the lack of reference data for small engines $\left(F_{o o}<26.7 \mathrm{kN}\right)$, turboprop and turboshaft engines; this lack of 
data prevents the simulation of emissions and the comparison with high by-pass ratio engines.

Only a few sparse data exist from turboprop/turboshaft engine manufacturers; data in the literature may include tests of military engines, for example, T700-GE-700 with different fuels (JP4, JP5), which yield different emission rates $^{22}$.

One argument sometimes put forward is that turboprop engines are designed to provide torque rather than thrust. Unless these engines are coupled to a propeller via a gearbox, no useful thrust is generated. However, it is contended here that combustion emissions are ultimately dependent on the combustor design and the aero-thermodynamic conditions inside the combustor, specifically the total entry temperature $T_{T 3}$, and the total pressure $P_{T 3}$ (or overall compression ratio $P_{R}$ ), hence some commonality should exist.

In this paper we propose the following argument: combustors for turbofan and turboprop engines should provide the same level of exhaust emissions, all other parameters being equal. Since the detailed conditions in the combustor are not known, we limit the analysis to correlations that use the overall pressure ratio $P_{R}$, and fuel flow $W_{f 6}$ (or specific fuel consumption, where available). Therefore, we propose data analysis from the ICAO databank to extract information that can be used for modelling emissions from torque-generating gas turbine engines.

There are several ways of showing the data in a graphical model. To avoid too many charts, a few representative examples will be provided here. The remaining post-processed data are made available in the supplementary material accompanying this paper.

\section{Statistical Emissions Model}

\subsection{Use of the ICAO Databank}

The ICAO spreadsheets include the certification data, which are nitrogen oxides $\left(\mathrm{NO}_{x}\right)$, carbon monoxide (CO), unburned hydrocarbons (UHC, or HC), smoke number, landing- and take-off (LTO) emissions relative to the rated thrust $\left(D_{p} / F_{o o}\right)$; the latter ones are limited by international conventions (the Committee on Aviation Environmental Protection, CAEP, a technical unit of the $\mathrm{ICAO})$.

The emission data are provided at four standard operating points, defined as take-off $\left(\mathrm{N}_{1} \%=\right.$ $100)$, climb-out $\left(\mathrm{N}_{1} \%=85\right)$, final approach $\left(\mathrm{N}_{1} \%=30\right)$ and idle mode $\left(\mathrm{N}_{1} \%=7\right)$. The calculation of landing and take-off emissions relies on the use of these modes for a specified length of time. Thus, the final estimate for LTO emissions is based on an algebraic equation: 


$$
E_{I}=\sum_{m=1}^{4} E_{I m} t_{m} W_{f 6 m}
$$

where $t_{m}[\mathrm{~s}]$ is the time in mode $m, W_{f 6 m}$ is the corresponding fuel flow $[\mathrm{kg} / \mathrm{s}]$, and $E_{I m}$ is the emission index $[\mathrm{g} / \mathrm{kg}]$. The result is an emission value in grams. This operation is repeated for all indices. Note that the emission data are given for a single engine at the operating conditions indicated by the manufacturers (ground conditions with a range of atmospheric temperatures and pressure); therefore, the LTO emissions of an aircraft must be corrected for the number of operating engines, and for the flight conditions (atmospheric effects and flight Mach number).

In Eq. 1 the times-in-mode $t_{m}$ work as weight factors in the final evaluation of an emission value. Thus, low emission indices for a long time (idle) may contribute to a comparable level of a high emission value for a short time (takeoff or climb-out).

When engines operate at different ratings (speeds or fuel flow), an interpolation of the emission indices is necessary. A numerical investigation carried out in the course of this work highlighted the fact that that a step-by-step integration of the emissions using interpolated values from the ICAO databank depends strongly on how the data are interpolated at the low end of the fuel flow. An example is shown in Figure 1, which refers to the emission rates of the turbofan CF34-10E7. The data points are obtained from 10 different flights recorded by the FDR. The ICAO reference points are indicated by circles which are not coincident with the ICAO points due to the non-linear relationship between fuel flow and gas turbine speed.

The interpolation of the data with respect to the fuel flow is the is the most appropriate for this scope and is in line with the behaviour indicated by studies on the CFM56 turbofan engine ${ }^{23}$. The double-log interpolation $\log N_{1} \log E_{I}$ leads to a considerable under prediction of emissions at low ratings, especially CO (as shown) and HC. This emphasises the difficulty and indeed the potential variability in the emissions at low values of thrust, as typically found on airport taxiways. The discrepancy between ICAO LTO emissions and emissions predicted using general part-load engine states increases with the idle-mode emission indices. 


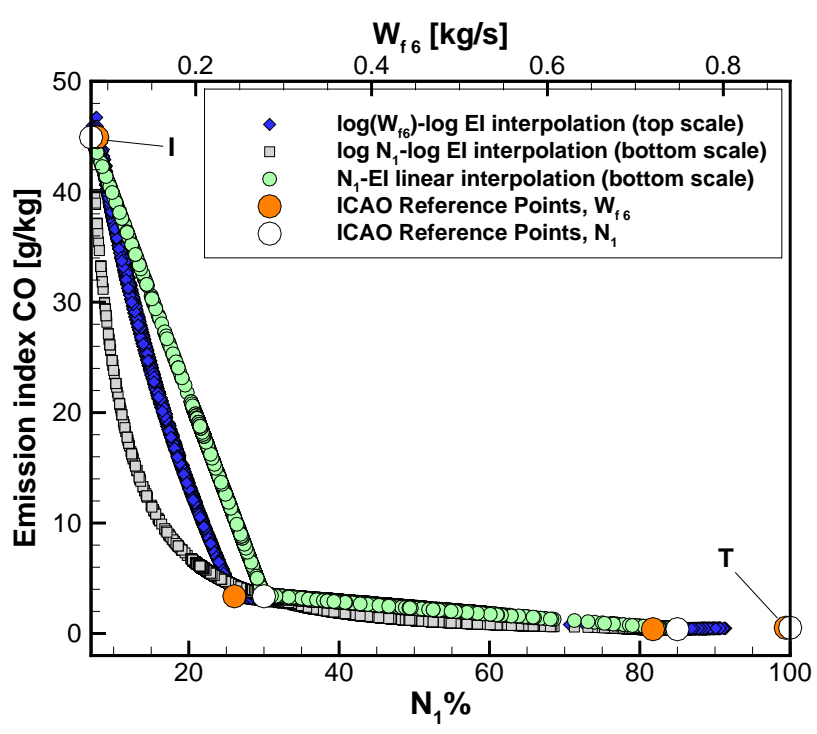

Figure 1: Interpolation of the CO emission index from the ICAO databank; turbofan engine CF3410E7. Points "I" and "T" are coincident.

\subsection{Data Analysis}

The ICAO data have been rearranged so as to exclude engines no longer in service, engines with superseded data, and data not directly relevant to the analysis shown in the foregoing discussion.For example, neither power extraction nor the fuel specification have been considered. No attempt has been made to separate low by-pass ratio (turbojet) from high bypass ratios (turbofan). However, a few turbojet engines were eliminated because of incomplete data (Rolls-Royce Spey). Other anomalies exist. For example, on a map of $\log \left(W_{f 6}\right)$ versus $\log \left(E_{I}\right)$ the emission indices of the AE3007 engines are out of step from all other engines.

The second step is to identify clear outliers in the remaining data. This step involves some level of judgment as to where a cut-off may lie. A filter was applied to identify the outliers in the remaining set. Three filter rules were used: 1.) engines test dates; 2.) thrust-specific fuel consumption; 3.) absolute values in relation to the average of a distribution. These rules were applied to the whole dataset in turn, and are described below.

Test Date. Consideration of test dates is somewhat arbitrary, as there is no clear cut off, and the database itself does not correlate easily with the test date. However, by choosing as a cut-off date the year 1980, only 22 engines are eliminated from the database (JT3, JT9, JT15, and earlier versions of the CF60); subsequent analysis shows that the scatter of the data and the residuals of the least 
square functions are improved with this choice. Scatter is further reduced on most emission indices if the cut-off date is moved further into the future, with the year 1990 being particularly useful for improving all correlations. However, maintaining the test date in the matrix allows additional insight into the direction of technological advances; these indicate clearly a direction toward higher pressure ratios, higher by-pass ratios and lower emissions. The final compromise was a cut-off test year of 1985, which leaves a database of approximately 400 engines. This choice removed some engines with large $\mathrm{HC}$ emissions in idle mode. Furthermore, this selection maintains a good number of samples at the low-end of the map: relatively low fuel flow coupled with relatively low pressure ratios, which is the domain of turboprop engines.

Thrust-Specific Fuel Consumption. For the take-off mode, the thrust-specific fuel consumption (TSFC) can be calculated from the ratio $W_{f 6} / F_{o o}$. Investigation of the TSFC distribution indicates that there is a ratio of $\sim 2.3$ between the worst and the best engine in the database. Those engines that have a TSFC $>\sim 15 \mathrm{mg} / \mathrm{Ns}$, and have been excluded from statistical analysis. The latter operation eliminates 10 engines (some JT8 and one JT15).

Mean Values. We then looked at the distribution of the emission indices. For each index, for example the take-off $\mathrm{NO}_{x}$, we compared the value for each engine with the average value of the distribution, $\bar{E}_{I}$. If engines are deselected when

$$
E_{I}>\max \left\{2 \bar{E}_{I}, \bar{E}_{I}+2.5 \sigma\right\} \text { or } \bar{E}_{I}=0
$$

at any of the four modes of operation, this leaves 200 engines in the database; this result was considered unreasonable. If the zero entries are maintained, only 30 engines are eliminated. If the filter Eq. 2 is applied separately to each operating mode, then only a few engines are eliminated at a time. In order to avoid losing essential information, the filter was applied on a mode-by-mode basis, which means that if an engine was excluded from the analysis of one emission index, it could have been retained in another emission index. No engines are eliminated for the take-off $\mathrm{NO}_{x}$ analysis, whilst 3 engines are deselected in the analysis of the idle-mode $\mathrm{HC}$ emission index. Note that that different filters may deselect the same engines, which indicates that the operation is robust to different criteria. In any case, the number of engines remaining in the database is just less than 400 if the reference year is 1985, and about 420 engines if the test date is pushed back to 1980 . 


\subsection{Data Sorting}

In order to provide explanations for observed trends, we have attempted to sort the engines. The only data available to differentiate the various engines are the by-pass ratio, the design pressure ratio, the rated output and the combustor type; the latter one is generally a commercial definition. Entry temperatures in the combustor are not given in the databank, and although the conditions could be simulated, the simulation was deemed not sufficiently accurate for the scope of the analysis that follows. The by-pass ratio is not thought to affect the conditions in the combustor, and the analysis appears to confirm that this is the case. A useful relationship can be found in some cases between the rated fuel flow $W_{f 6}$ and the design pressure ratio, $P_{R}$. The case for $\mathrm{NO}_{x}$ emissions at take-off ratings is shown in Figure 2. There appears to be two separate clouds of points. These points have thus been separated into two sub-sets that are fitted with linear least squares. The legend on the top left corner indicates the main engine families in each sub-set. The discriminating factor for the two sub-sets was a derivative $d W_{f 6} / d P_{R}=1.62 / 15 \simeq 0.085$ (this corresponds roughly to a line between the two linear correlations in Figure 2a). When the two sets of data are corrected for their rated thrust, they eventually collapse around a single line, as indicated in Figure 2b. Therefore, for the take-off mode, least-square functions are sought in terms of the TSFC- $P_{R}$ combination.

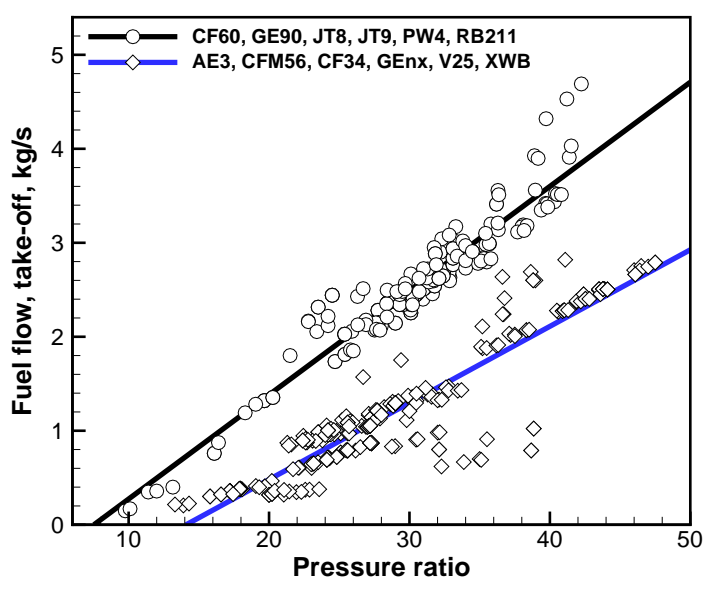

(a) $W_{f 6}$

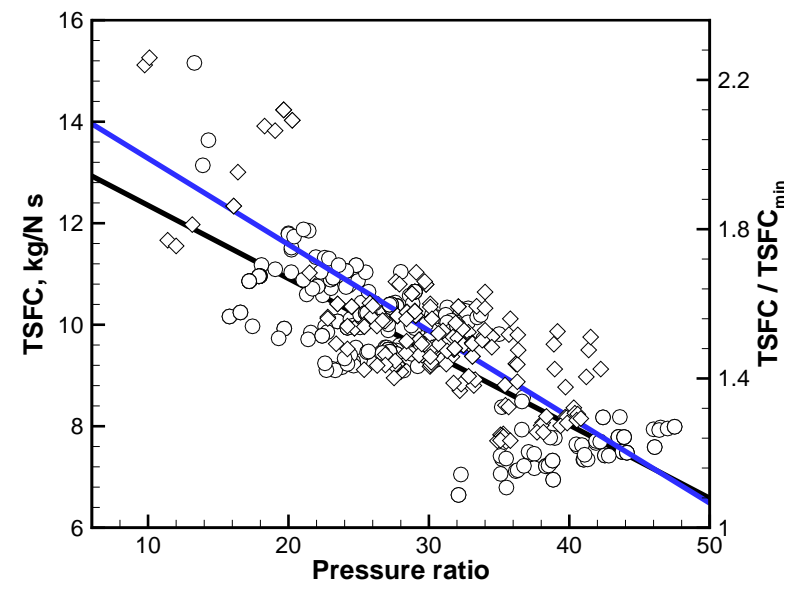

(b) TSFC

Figure 2: Relationship between take-off fuel flow and design pressure ratio.

\subsection{Interpolating Functions}

All the emissions have been fitted with a surface defined by 


$$
z\left(x_{1}, x_{2}\right)=a+b x_{1}+c x_{1}^{2}+d x_{2}+e x_{2}^{2}+f x_{1} x_{2}
$$

where $\left\{x_{1}, x_{2}\right\}$ are two independent parameters. We assumed that there is a parabolic dependence on each parameter plus a cross-dependence via the coefficient $f$. Linear equations such as

$$
z\left(x_{1}, x_{2}\right)=a_{1}+b_{1} x_{1}+c_{1} x_{2}+d_{1} x_{1} x_{2}
$$

have also been considered. In most cases, the RMS of the residuals $(r=\sqrt{W S S R / D o F})$ and the variance of the residuals $\sigma=(W S S R / D o F)$ was lower if Eq. 3 was used. No weights were used in the interpolation. In any case, the sum of residuals is relatively large, meaning that surface fits are not inclusive of most data points. There is no unique way of seeking best fits, as these depend on the equations chosen, on the weights used, the numerical procedure applied and on the consideration of outliers, which in some cases have an exaggerated effect on the final correlation. The least-squares method used for the determination of the coefficients of Eq. 3 and Eq. 4 is that of Levenberg-Marquardt, programmed for this scope. The best fit minimises the distance

$$
\sum_{i}\left[z_{i}\left(x_{1 i}, x_{2 i}\right)-z\left(x_{1}, x_{2}\right)\right]^{2}
$$

between value $z_{i}$ and the corresponding surface $z\left(x_{1}, x_{2}\right)$ The coefficients of the correlation analysis are given in the Appendix. For all the operating modes, least-square surfaces are calculated using the TSFC- $P_{R}$ combination.

The largest emission indices are generally $\mathrm{NO}_{x}$ in take-off mode, $\mathrm{CO}$ in idle mode and $\mathrm{HC}$ in idle mode. These specific cases are illustrated with some graphs, Figures 3, 4 and 5. In Figure 3 we show the result of the analysis for the $\mathrm{NO}_{x}$ emission index, and in Figure 4 we show the HC emission indices in idle mode. The graphs show two separate sub-sets of data: those engines having a TALON combustor ${ }^{18}$ and those engines having a TAPS combustor ${ }^{17}$.

The emission indices of these combustors (applied, respectively to GEnx engines and PW1series) are considerably below the reference surfaces; this indicates that emissions are substantially cut in comparison with other high by-pass turbofans. In fact, at pressure ratios of $P_{R} \simeq 35$, these emissions are about half of the average in the database. The margins are not so evident at other modes, and in fact, in idle the data points for this engine series are virtually on the best fit surface, Eq. 3. 


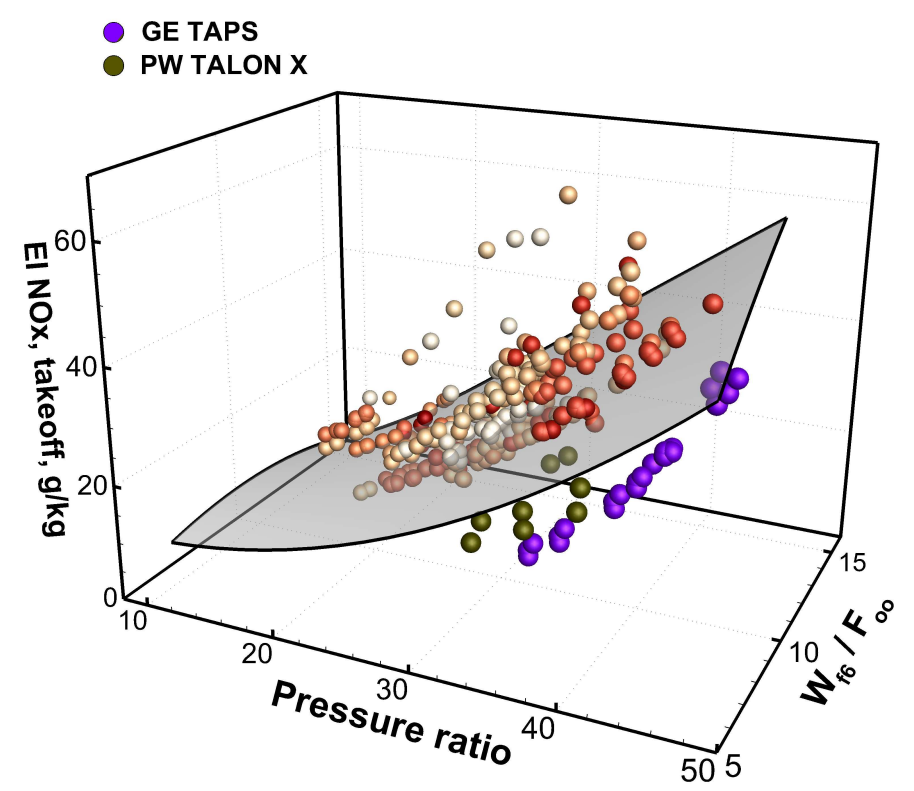

Figure 3: Best fit surface for $\mathrm{NO}_{x}$ emissions at take-off; data points coloured according to test date (darker shades denote new test dates). Test date cutoff is 1985.

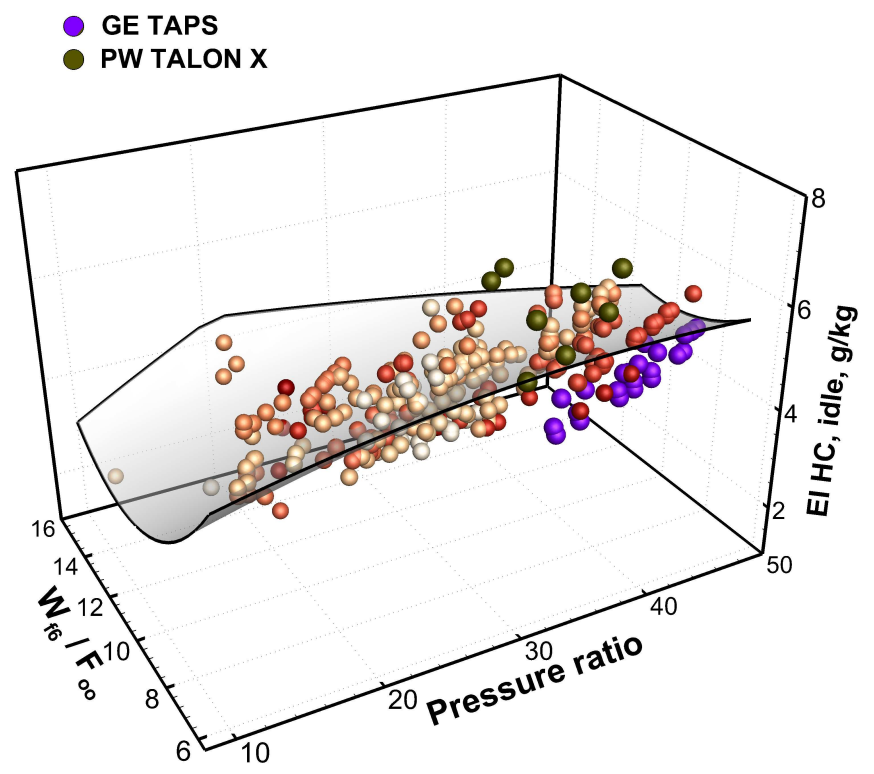

Figure 4: Best fit surface for HC emissions in idle mode; data points coloured according to test date (darker shades denote new test dates). Test date cutoff is 1985.

Once the least-square functions are determined (see also coefficients given in Appendix A), we define the relative error, for each engine in the database:

$$
E=\frac{E I_{I C A O}-E I_{\text {interp }}}{E I_{I C A O}}
$$




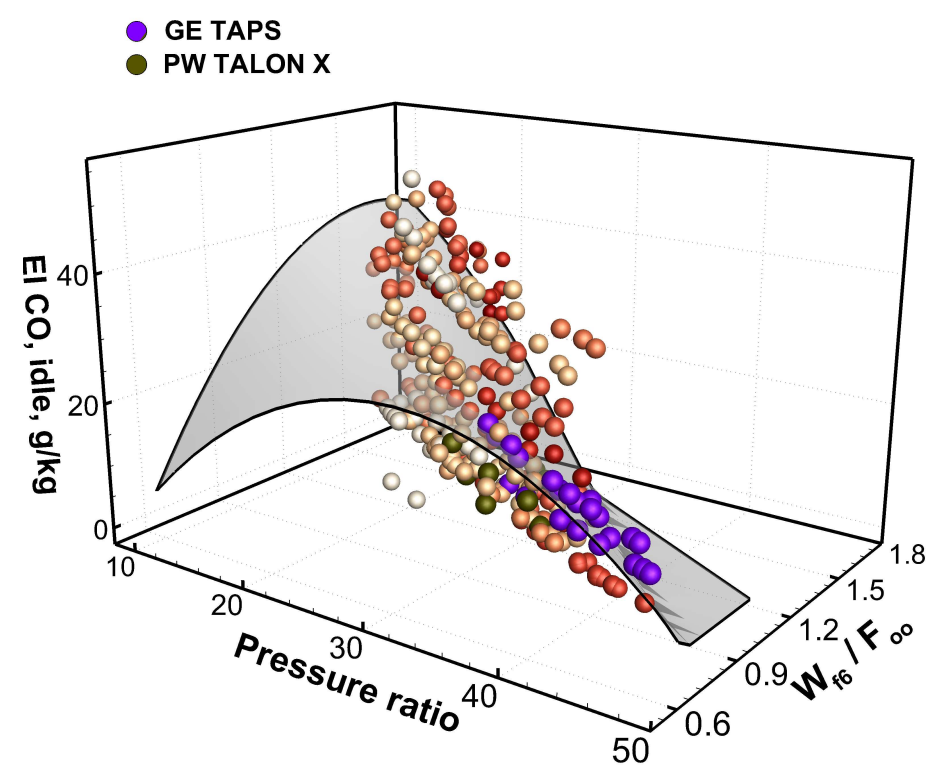

Figure 5: Best fit surface for $C O$ emissions in idle mode; data points coloured according to test date (darker shades denote new test dates). Test date cutoff is 1985.

This error is only calculated for non-zero emission entries only. A statistical analysis is applied to this error, which indicates that the standard deviation on the smoke number is rather large $\left(E>10^{2}\right.$ in most cases), and thus this interpolation is not reliable for this quantity.

\section{Extrapolation to Turboprop Engines}

As indicated in the foregoing analysis, a critical effect on engine emissions cannot be determined: this requires the introduction of another parameter, since the scatter of the data is large. This scatter includes clear outliers, as well as zero-emission data, all of which have been included in the statistical analysis. With this caveat in mind, the same empirical relationships are proposed for turboprop engines. Only approximate pressure ratios and take-off fuel flow data can be inferred from engine manufacturers. Interpolation of data is then executed with independent variables $P_{R}$ and $W_{f 6}$.

Fuel flow data at the ICAO reference conditions are not available for these engines. In Figure 6 we show the uninstalled fuel flow and shaft power from one turboprop engine for which data were available (turboprop PW127F), with the data normalised to the take-off power setting. The reference data indicate two different idle states: flight and ground idle, the latter being $N_{1}=3 \%$, most likely with a static propeller. 


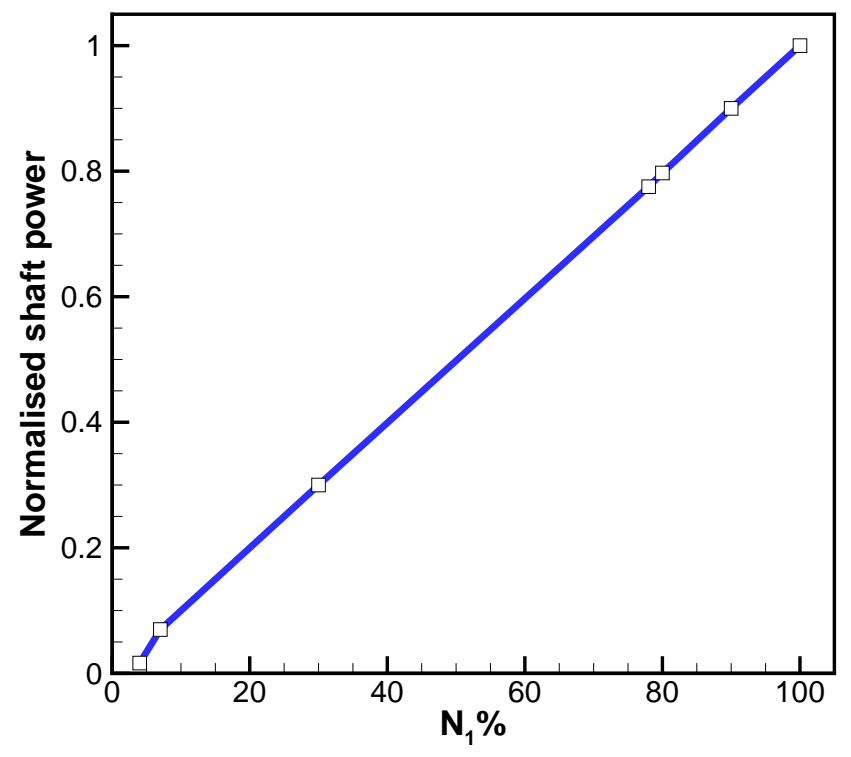

Figure 6: Uninstalled shaft power of a turboprop engine at standard sea level conditions.

In reality, the relationship $\mathrm{N}_{1}-\mathrm{W}_{f 6}$ is not linear and is likely to depend on the specific engine. An example is shown in Figure 7 which refers to fuel flow data extracted from the Flight Data Recorder of Bombardier Dash8 Q400 airplanes powered by PW150A turboprops. This is a case of real-life operation, in contrast to a new, uninstalled engine. A few important facts are highlighted. First, the data are for a full flight, from gate to gate, and thus include both low and high power settings, atmospheric effects and engine intake distortion (installation and propeller's induced flow). Second, at $N_{1} \% \simeq 95$ there is a sharp increase in fuel flow, with a corresponding increase in shaft torque, e.g. the gas generator turbine never reaches the $100 \%$ speed required by the ICAO standard settings. Finally, the fuel flow drops to zero at engine speeds of the order of 25-30\%. Therefore, idle conditions can be interpreted as $\mathrm{N}_{1} \%=25$, in contrast to the prescribed ICAO values. Since turboprop and turboshaft engines are coupled with rotating systems, requiring a minimum of torque to operate, it is possible that the relevant idle mode has turbine speed of the order of $20 \%$, rather than $7 \%$, as in the case of the turbofan engines.

Figure 8 shows another case for the same engine, but for a different airplane. Note that left and right engines have different fuel flow rates, but the general trend is the same as that in Figure 7 . Engine power data are not available, but have inferred from the product between torque and $N_{1}$.

The $\mathrm{N}_{1}$-power relationship has been verified for other engines by using a one-dimensional aerothermodynamic model ${ }^{24 ; 25}$. In absence of more rigorous data, for the fuel flow we propose the power 


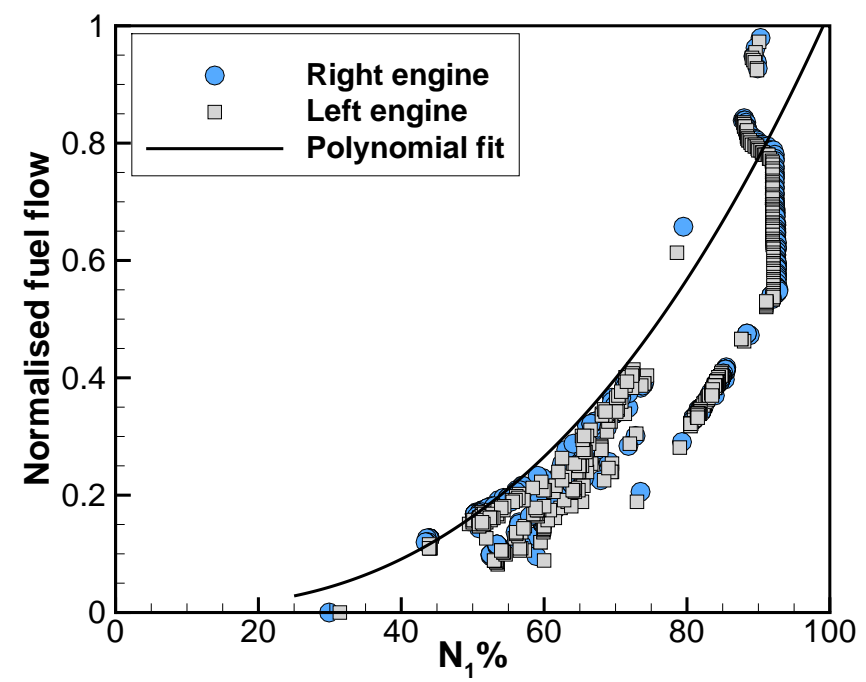

Figure 7: Fuel flow data for a PW150A turboprop engines operating on a Bombardier Q400 airplane, over the complete flight.

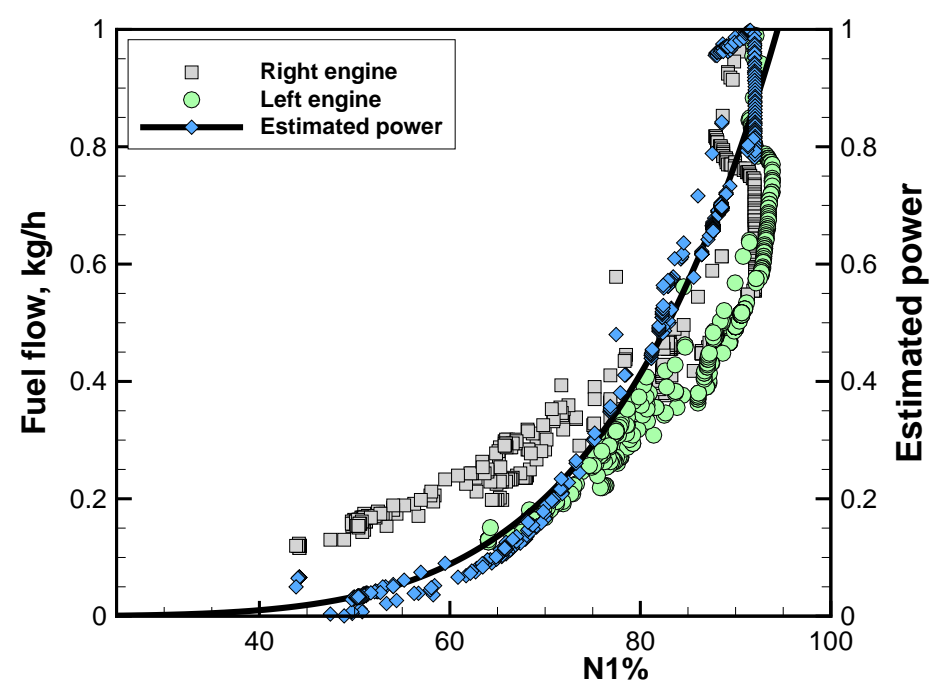

Figure 8: Fuel flow and power data for a PW150A turboprop engines operating on a Bombardier Q400 airplane, over the complete flight.

fit

$$
W_{f 6}=\exp \left(4.459 \cdot 10^{-2} N_{1}-4.098\right)
$$

This equation is expressed by the average solid line in Figure 7, and represents conditions at sea level (approximately).

Additional problems are encountered in the analysis of emission data for this class of gas turbine 
engines. First, turboprops can deliver a non negligible amount of residual thrust; thus, these power plants deliver a mix of torque and jet thrust. Turboshaft engines deliver almost exclusively torque; only minimal residual energy is available from the exhaust gases. Turboshaft engines are the power plant of choice of modern helicopters, where the exhaust may have to be diverted away from the engine axis. Therefore, residual thrust is of no use.

A graphical example of the correlations used is displayed in Figure 9, where we have used the only available and approximate data for turboprop and turboshaft engines. The relatively small pressure-ratio and fuel flow range of these engines indicates that they are placed in a small corner of the map, and sometimes they fall off the bounds of the ICAO database. For example, the minimum pressure ratio in the database used for the present analysis is 9.76 (engine JT15D.01S), whilst many turboprop engines have pressure ratios below this value. In recent years these pressure ratios have increased almost uniformly to $P_{R}>14$. Therefore, correlations at this low end of the independent parameters need further data points to be deemed robust.

A similar analysis is shown for the $\mathrm{NO}_{x}$ emissions in idle mode, Figure 10. The pointed arrow indicates the range of emission indices over a very narrow band of pressure ratios and fuel flow. Only sparse emission data (large symbols) could be inferred for this case.

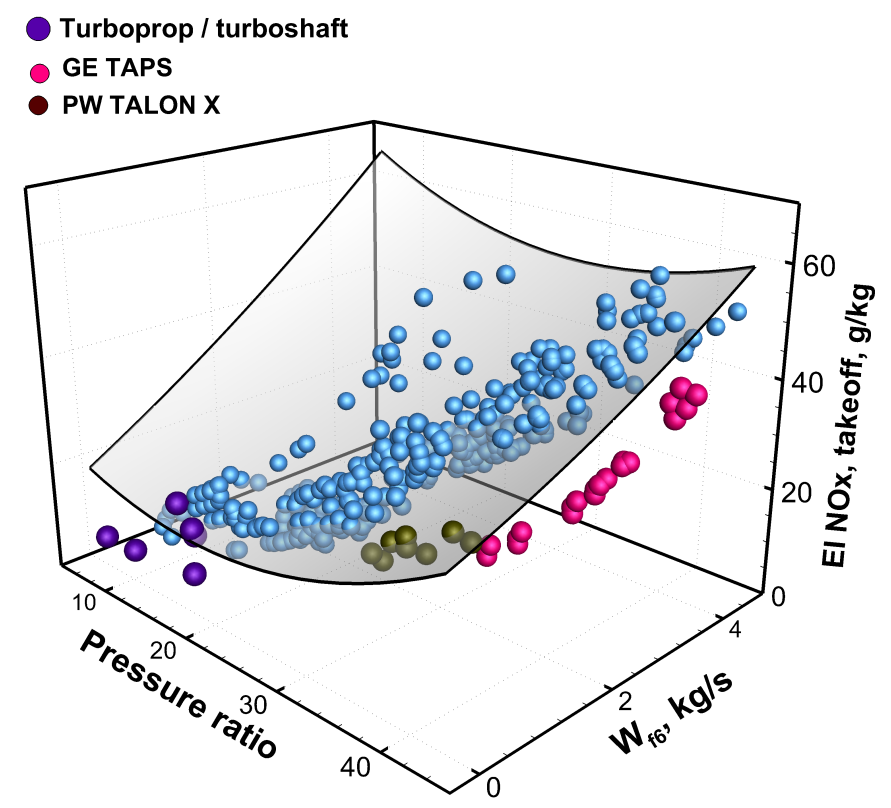

Figure 9: Best fit surface for $\mathrm{NO}_{x}$ emissions at take-off. 


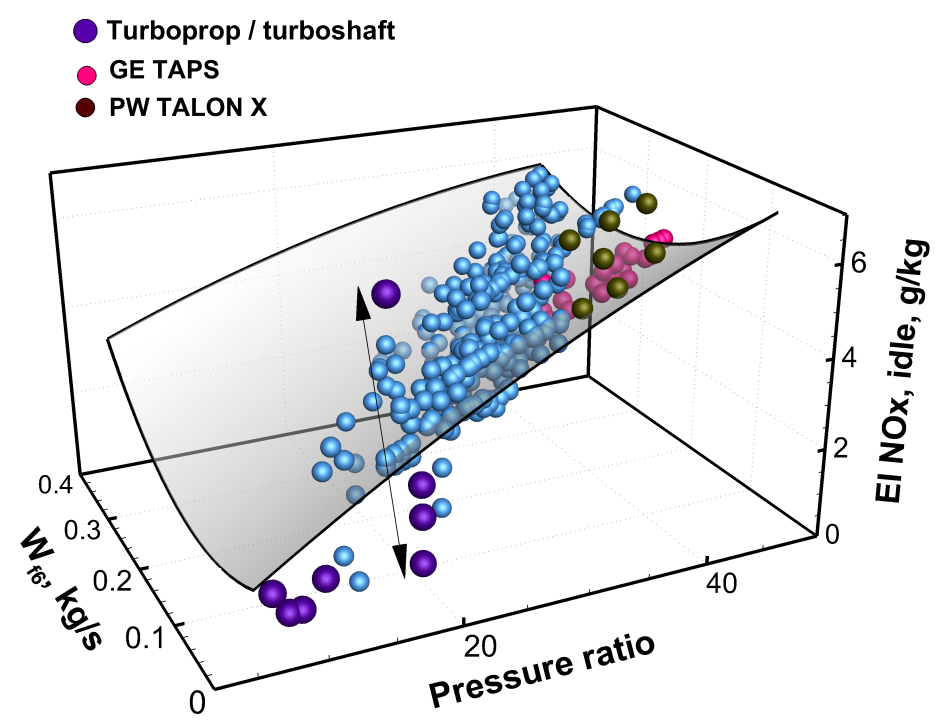

Figure 10: Best fit surface for $\mathrm{NO}_{x}$ emissions in idle mode.

\subsection{Emission Index Model}

The process for estimating the emission indices for $\mathrm{NO}_{x}, \mathrm{CO}$, and $\mathrm{HC}$ for turboprop and turboshaft engines is as follows:

1. The ICAO database for turbofan engines is processed on a case-by-case basis and least-square surfaces such as Eq. 3 are produced; 6 coefficients are determined for each emission index (see Table A1). The independent variables for the least-squares are the fuel flow $W_{f 6}$ and the overall pressure ratio of the turbofan engines.

2. For turboprop and turboshaft engines, the pressure ratios and the take-off fuel flows are inferred from open-source documents, official or otherwise.

3. For operating modes other than take-off, fuel flow data at standard atmospheric conditions are determined from surrogate equations, such as Eq. 7, which in a general form is written as

$$
W_{f 6}=\exp \left(a N_{1}+b\right)
$$

4. The operating modes of these engines are set to $N_{1} \%=20,30,85,100$ (as a result of the analysis in Figure 7.) The corresponding emission data are "reference" emission indices, REI. 
5. Reference emission indices are determined by using the atmospheric conditions recommended in the Boeing Fuel Flow Model $2^{26}$, which are reported here:

$$
E I_{C O}=R E I_{C O}\left(\frac{\theta^{3.3}}{\delta^{1.02}}\right), \quad E I_{H C}=R E I_{H C}\left(\frac{\theta^{3.3}}{\delta^{1.02}}\right), \quad E I_{N O x}=R E I_{N O x}\left(\frac{\delta^{1.02}}{\theta^{3.03}}\right) e^{h m}
$$

where $h m$ is a humidity correction.

6. For a given value of the fuel flow $W_{f 6}$ the corresponding emission index is calculated by interpolation as discussed in $\S 2$.

An exponential Mach number correction is used in the Boeing fuel flow model; this correction does not apply in the general case, with polynomial fits being more appropriate in some cases.

\section{Results and Discussion}

The emission model proposed is applied to the prediction of exhaust emissions from the turboprop aircraft Bombardier Dash8 Q400, powered by the PW150A engine (see Figure 7). The computer model used is FLIGHT, which is widely documented (see for example ${ }^{24 ; 25}$ ). The code now predicts emissions for $\mathrm{NO}_{x}, \mathrm{CO}, \mathrm{HC}, \mathrm{SO}_{x} \mathrm{H}_{2} \mathrm{O}$, and soot, which are separated as LTO, stratospheric emissions, and cumulative.

In both cases, a short commuter flight (400 km, $216 \mathrm{n}$-miles) is considered. The required range has little effect on the LTO emissions, except for the $\mathrm{CO}_{2}$, which have been studied separately ${ }^{6}$. LTO emissions depend on the amount of time spent on the ground, the idle times and actual flight procedures. We assume that taxi times are as stipulated by the ICAO (16 minutes outbound + 10 minutes inbound). In all cases, we consider a passenger load of $90 \%$, standard atmospheric conditions, no winds, and airfield altitude near sea level. The present calculation of the LTO emissions consists of 6 phases: taxi-out, take-off, climb-out, final approach, landing, and taxi-in. Therefore, a comparison with the standard procedure will show some discrepancies.

\subsection{Embraer E195 with CF34-10E engine}

We now consider the case of a commuter airplane powered by turbofan engines, the General Electric CF34-10E7 (ICAO Databank version 23, engine ID number: 8GE119). For this aircraft we have a set of $10 \mathrm{FDR}$ data logs for commuter flights. These data give parameters such as airspeed, fuel 
flow rate and aircraft mass for each flight stage, which are inputted into FLIGHT to estimate the emissions based on power setting. The LTO emissions are summarised in Table 1 in the appendix. The calculations were carried out by using Eq. 1 with the appropriate emission indices, the times and the fuel flows extracted from the flight data recorders.

It is observed that there is a large discrepancy between the calculated emissions and the emissions estimated by a straightforward application of the ICAO method (demonstrated in Figure 1), in particular for carbon-oxides and uncombusted hydrocarbons; there is more than one order of magnitude in the discrepancy of $\mathrm{CO}$ emissions and a factor $\sim 2$ for the $\mathrm{HC}$ emissions. There is a number of factors to take into fuhrer account. First, the engine speed seldom exceeds $90 \%$ (causing a reduction in $\mathrm{NO}_{x}$ emissions at take-off), it rarely goes below $20 \%$ (causing a large reduction in idle $\mathrm{NO}_{x}$ ). In fact, the time in idle is virtually zero for all the flights considered.

Second, the LTO times are on average $\sim 5$ minutes shorter than the standard values, mostly due to shorter ground roll. The calculated emissions do not include corrections for engine installation losses, since the fuel flow data are taken directly from the FDR files. The emission indices are corrected for atmospheric effects (pressure, temperature, relative humidity) intake ram pressure, following the Boeing model. The ICAO emission estimates are as indicated in the engine test documentation and are multiplied by two to take into account two operating engines. The calculations using the present model are shown in the bottom row. These data show that the statistical estimates of the exhaust emissions are much closer to the actual flights than to the ICAO estimates.

Although a limited set of FDR data has been used, the result indicates that there can be wide discrepancies between the use of standard data and actual emissions, and it is not unlikely that some aircraft emissions are estimated in large excess. 
Table 1: LTO exhaust emissions of an Embraer E195 with CF35-10E7 engines; $D_{F}=D_{p} / F_{o o}$.

\begin{tabular}{rrrrrrrrrrrrr}
\hline Flight & $\begin{array}{r}\text { Fuel } \\
{[\mathrm{kg}]}\end{array}$ & $\begin{array}{r}\mathrm{NO}_{x} \\
{[\mathrm{~g}]}\end{array}$ & $\begin{array}{r}\mathrm{CO} \\
{[\mathrm{g}]}\end{array}$ & $\begin{array}{r}\mathrm{HC} \\
{[\mathrm{g}]}\end{array}$ & $\begin{array}{r}D_{F} \\
{\left[\mathrm{NO}_{x}\right]}\end{array}$ & $\begin{array}{r}D_{F} \\
{[\mathrm{CO}]}\end{array}$ & $\begin{array}{r}D_{F} \\
{[\mathrm{HC}]}\end{array}$ & $\begin{array}{r}\mathrm{SO}_{x} \\
{[\mathrm{mg}]}\end{array}$ & $\begin{array}{r}\mathrm{H}_{2} \mathrm{O} \\
{[\mathrm{kg}]}\end{array}$ & $\begin{array}{r}\mathrm{LTO} \\
{[\mathrm{min}]}\end{array}$ & $\begin{array}{r}\mathrm{N}_{1 \min } \\
{[\%]}\end{array}$ & $\begin{array}{c}\mathrm{N}_{1 \max } \\
{[\%]}\end{array}$ \\
\hline 1 & 318.5 & 3194.7 & 6500.6 & 613.5 & 38.17 & 77.67 & 7.33 & 254.8 & 394.0 & 33.8 & 7.8 & 91.8 \\
2 & 268.4 & 3204.2 & 3074.6 & 281.1 & 38.28 & 36.73 & 3.36 & 214.8 & 332.1 & 19.2 & 10.8 & 91.9 \\
3 & 359.0 & 4561.3 & 4080.8 & 374.8 & 54.50 & 48.75 & 4.48 & 287.2 & 444.1 & 25.3 & 7.8 & 90.3 \\
4 & 352.7 & 3830.2 & 5854.0 & 548.1 & 45.76 & 69.94 & 6.55 & 282.1 & 436.2 & 31.9 & 18.8 & 90.9 \\
5 & 355.3 & 4029.2 & 4938.7 & 456.1 & 48.14 & 59.00 & 5.45 & 284.2 & 439.5 & 29.7 & 7.5 & 91.1 \\
6 & 278.8 & 3203.9 & 2696.0 & 234.2 & 38.28 & 32.21 & 2.80 & 223.0 & 344.8 & 18.8 & 7.6 & 90.1 \\
7 & 134.3 & 1328.6 & 2238.4 & 205.1 & 15.87 & 26.74 & 2.45 & 107.4 & 166.1 & 12.2 & 19.5 & 91.8 \\
8 & 322.3 & 3399.5 & 5660.1 & 528.3 & 40.61 & 67.62 & 6.31 & 257.8 & 398.6 & 31.0 & 20.4 & 91.9 \\
9 & 356.5 & 3975.0 & 5899.8 & 552.9 & 47.49 & 70.49 & 6.61 & 285.2 & 441.0 & 32.2 & 7.9 & 89.9 \\
10 & 386.5 & 4412.2 & 5279.6 & 480.3 & 52.71 & 63.08 & 5.74 & 309.2 & 478.2 & 31.4 & 7.8 & 89.9 \\
\hline Average & 3596 & 4682 & 432 & & & & & & 27.0 & & 7.2 & \\
$\sigma$
\end{tabular}

\subsection{Bombardier Q400}

The Bombardier Q400 is a medium-range commercial aircraft powered by two turboprop engines.

The predicted reference emission indices for this aircraft are provided in Table 2.

Table 2: Predicted emission indices for the PW150A. All data are $[\mathrm{g} / \mathrm{kg}]$.

\begin{tabular}{lrrr}
\hline & $\mathrm{NO}_{x}$ & $\mathrm{CO}$ & $\mathrm{HC}$ \\
\hline Takeoff & 16.089 & 0.588 & 0.093 \\
Climbout & 12.636 & 0.669 & 0.109 \\
Approach & 7.003 & 6.001 & 0.328 \\
Idle & 3.305 & 32.703 & 4.162 \\
\hline
\end{tabular}

As in the previous case, a number of FDR data packs were available. These data have been used to predict the LTO emissions using the emission indices in Table 2. The sampling rate of the data is 1s for the fuel flow and 4s for the GPS position. Each engine was considered separately, because of different fuel flows, such as those shown in Figure 8. Thus, the incremental emissions $\Delta m$ at a generic time step are

$$
\Delta m=E_{I}\left[W_{f 6}(1)+W_{f 6}(2)\right] \Delta t
$$

with the appropriate emission index $E_{I}$ from Table 2 and with corrections described in $\S 3.1$. The predicted emissions are summarised in Table 3. The flight time includes all operations below 3,000 
feet. Note that flight number 5 has only a brief duration below the threshold altitude. Flight times are slightly different from the ICAO standard, as are the engine speeds during the various phases of flight.

Table 3: Predicted LTO emissions for the Bombardier Q400 turboprop airplane with PW150A engines.

\begin{tabular}{lcrrrrrrrrrr}
\hline & ORIG & DEST & $\begin{array}{r}\text { Fuel } \\
{[\mathrm{kg}]}\end{array}$ & $\begin{array}{r}\text { time } \\
{[\mathrm{min}]}\end{array}$ & $\begin{array}{r}\mathrm{N}_{1 \min } \\
{[\%]}\end{array}$ & $\begin{array}{r}\mathrm{N}_{1 \max } \\
{[\%]}\end{array}$ & $\begin{array}{r}\mathrm{NO}_{x} \\
{[\mathrm{~g}]}\end{array}$ & $\begin{array}{r}\mathrm{CO} \\
{[\mathrm{g}]}\end{array}$ & $\begin{array}{r}\mathrm{UHC} \\
{[\mathrm{g}]}\end{array}$ & $\begin{array}{r}\mathrm{SO}_{x} \\
{[\mathrm{mg}]}\end{array}$ & $\begin{array}{r}\mathrm{H}_{2} \mathrm{O} \\
{[\mathrm{kg}]}\end{array}$ \\
\hline 1 & ABZ & MAN & 172.6 & 35.7 & 64.0 & 94.3 & 2102.1 & 146.5 & 21.4 & 138.1 & 213.5 \\
2 & BHD & MAN & 175.4 & 32.9 & 21.5 & 94.1 & 2166.8 & 147.6 & 21.6 & 140.3 & 217.0 \\
3 & EDI & MAN & 181.0 & 36.0 & 20.1 & 93.5 & 2183.4 & 167.2 & 23.3 & 144.8 & 223.9 \\
4 & MAN & NWI & 182.9 & 35.6 & 63.9 & 94.4 & 2244.1 & 149.9 & 22.4 & 146.3 & 226.3 \\
5 & MAN & JER & 121.8 & 17.2 & 67.4 & 94.1 & 1567.5 & 86.1 & 14.0 & 97.5 & 150.7 \\
6 & MAN & GLA & 185.2 & 37.7 & 20.6 & 94.5 & 2266.8 & 158.0 & 23.1 & 148.2 & 229.1 \\
7 & MAN & INV & 193.8 & 37.2 & 39.0 & 94.5 & 2380.0 & 157.6 & 23.7 & 155.0 & 239.7 \\
8 & NQY & MAN & 171.7 & 31.7 & 40.9 & 93.8 & 2115.8 & 139.9 & 20.9 & 137.4 & 212.5 \\
9 & SOU & MAN & 166.5 & 33.9 & 24.9 & 93.5 & 2055.1 & 137.2 & 20.3 & 133.2 & 206.0 \\
\hline \multicolumn{2}{l}{ Average } & & & 33.1 & & & 2120.2 & 143.3 & 21.2 & & \\
$\sigma$ & & & 6.3 & & & 229.3 & 23.4 & 2.9 & & \\
\hline
\end{tabular}

The time in idle mode (defined as the time when $N_{1 g g}<20 \%$ ) is virtually zero in all the flights considered. This means that the predicted $\mathrm{HC}$ emissions are likely to be considerably lower than those calculated following the ICAO methodology, if the emission indices were known. Similar conclusions have been demonstrated in a recent paper by Turgut et al. ${ }^{27}$.

It is noted that there is a factor $\sim 1.5$ between maximum and minimum $\mathrm{NO}_{x}$, a factor $\sim 2$ for the CO, and so on. Therefore, Table 3 makes it clear that accuracy in the emission indices alone is not a guarantee for accurate prediction of exhaust emissions from actual flights. An error of $50 \%$ on any of the indices used for the prediction of a "standard" flight would be no worse than a set of accurate emission indices applied to a set of actual flights. The best use of the emission indices is in differential analysis, e.g. in cases where it is possible to compare, without doubt, two or more different operations with the same airplane and the same engines.

\section{Conclusions}

Double-digit variability has been found in most gas turbine emissions data. Although the recent trend is toward lower emissions across all engine sizes, there remains a spread of performance data. Manufacturers promising "double-digit improvements in environmental emissions" rely on data 
averages for comparisons. These data may include old engines with poor environmental performance. A number of conclusions have been reached in this study.

First, a statistical analysis has been proposed from the ICAO databank to predict emissions of modern engines not already covered in the public domain, specifically turboprops and turboshaft engines. The analysis set a cut-off test date to 1985, but otherwise no weights have been used in the statistical analysis. The ICAO databank indicates that there is a wide spread of emission indices due to a variety of effects, not least the technology level; this is identified almost exclusively by the year of certification and the combustor technology (where available).

Second, a general correlation for emission indices has been proposed for turbofan engines, to be used in preliminary design, or in cases where actual emission data are not available. With some caveats, the emission model could be used for small engines, keeping in mind that the proposed functions would provide extrapolations outside the data matrix.

Third, it is demonstrated that the interpolation of the emission indices at a generic point in the engine's flight envelope depends strongly on the interpolation method, and inaccuracies increase toward the low-end of the engine speeds (idle mode). For the turboprop engines, this study proposes to review the definition of idle mode. In this instance, a value of $N_{1}=20 \%$ has been used.

A further step was aimed at proposing a simple method for predicting emissions from turboprop engines. A method has been described to correct the indices for atmospheric conditions. This emissions model proposed is suitable for cases where no real-life data are available; this includes preliminary aircraft design (with few design data available), operational optimisation, and evaluation of exhaust emissions from aggregate flights.

Finally, an analysis was carried out on two airplanes for which FDR data where available: a turboprop Bombardier Q400 and an turbofan commuter airplane, Embraer E195. In the latter case, it is shown that there is a wide scatter of emissions, possibly due to operational aspects. However, the predictions obtained with the emissions model proposed (assuming that the emission indices were unknown), provides a better estimate for the LTO emissions that the standard ICAO model. This result emphasises again that the ICAO method for LTO emissions does not reflect real-life cases.

For the turboprop engine model, emissions were predicted using a selected number of FDR data and the surrogate emission model. Also in this case, a variability of emissions has been detected, which is mostly attributed to the airplane itself, the engine state, and the operational procedures. 
The application shown can be expanded to other engines for which emissions data are not available. Also, detailed analysis can be performed with FDR data of other airplanes to further verify the approach proposed in this contribution.

\section{References}

[1] Kim B, Fleming G, and Lee J Waitz I et al. System for assessing aviation's global emissions (SAGE), Part 1: Model description and inventory results. Transportation Research, Part D, 12(5):325-346, 2007. DOI:10.1016/j.trd.2007.03.006.

[2] Wilkerson JT, Jacobson MZ, Malwitz A, Balasubramanian S, Wayson R, Fleming G, and Naiman AD Lele SK. Analysis of emission data from global commercial aviation: 2004 and 2006. Atmos. Chem. Phys, page 6391V6408, 2010. DOI:0.5194/acp-10-6391-2010.

[3] Eyers C, Norman P, Middel J, Plohr M, Michot S, Atkinson K, and Christou RA. AERO2K global aviation emissions inventories for 2002 and 2025. Technical Report 04/011113, QinetiQ, 2004 .

[4] Masiol M and Harrison RM. Aircraft engine exhaust emissions and other airport-related contributions to ambient air pollution: A review. Atmospheric Environment, 95:409-455, 2014. DOI:10.1016/j.atmosenv.2014.05.070.

[5] Anon. ICAO Engine Emissions Databank, Version 23. Available in electronic format from the EASA website, 2017.

[6] Filippone A. Analysis of carbon-dioxide emissions from transport aircraft. J. Aircraft, 45(1):183-195, Jan. 2008. doi:10.2514/1.31422.

[7] A. Nuic. User Manual for the Base of Aircraft Data (BADA) - Revision 3.6. Eurocontrol Experimental Center, Bretigny-sur-Orge, France, July 2004. Note 10/04.

[8] Timko MT, Herndon SC, and Wood EC et al. Gas turbine engine emissions - Part I: Volatile organic compounds and nitrogen oxides. ASME J. Eng. Gas Turbines Power, 132(6):061504, 2010. DOI:10.1115/1.4000131.

[9] Timko MT, Onasch TN, and Northway MJ et al. Gas turbine engine emissions - Part II: Chemical properties of particulate matter. ASME J. Eng. Gas Turbines Power, 132(6):061505, 2010. DOI:10.1115/1.4000132. 
[10] Schürmann G, Schäfer K, Jahn C, Hoffmann H, Bauerfeind M, Fleuti E, and Rappenglück B. The impact of NOx, CO and VOC emissions on the air quality of Zurich airport. Atmospheric Environment, 41(1):103 - 118, 2007. DOI:10.1016/j.atmosenv.2006.07.030.

[11] Zhenhong Yu, Liscinsky DS, Fortner EC, Yacovitch TI, Croteau P, Herndon SC, and MiakeLye RC. Evaluation of PM emissions from two in-service gas turbine general aviation aircraft engines. Atmospheric Environment, 160:9-18, 2017. DOI:10.1016/j.atmosenv.2017.04.007.

[12] Lee J, Waitz I, Kim B, Fleming G, Maurice L, and Holsclaw C. System for assessing aviation's global emissions (SAGE), Part 2: Uncertainty assessment. Transportation Research, Part D, 12(5):381-395, 2007. DOI:10.1016/j.trd.2007.03.006.

[13] Senzig DA, Fleming GG, and Iovinelli RJ. Modeling of terminal-area airplane fuel consumption. Journal of Aircraft, 46(4):1089-1093, July 2007. DOI:10.2514/1.42025.

[14] Carslaw DC, Ropkins K, Laxen D, Moorcroft S, Marner B, and Williams ML. Near-field commercial aircraft contribution to nitrogen oxides by engine, aircraft type, and airline by individual plume sampling. Environ. Sci. Techn., 42(6):1871-1876, 2008. DOI:10.1021/es071926a.

[15] Lukachko SP and Waitz IA. Effects of engine aging on aircraft NOx emissions. In ASME Gas Turbine Conference, Paper 97-GT-388, Orlando, FL, June 1997. DOI:10.1115/97-GT-386.

[16] Lee JJ, Lukachko SP, Waitz IA, and Schafer A. Historical and future trends in aircraft performance, cost and emissions. Ann. Rev. Energy \&6 Environment, 26:167-200, 2001. DOI:10.1146/annurev.energy.26.1.167.

[17] Foust M, Thomsen D, Stickles R, Cooper C, and Dodds W. Development of the GE aviation low emissions TAPS combustor for next generation aircraft engines. AIAA paper 2012-0936, Nashville, TN, Jan 2012. DOI:10.2514/6.2012-936.

[18] McKinney R, Cheung A Sowa W, and Sepulveda D. The Pratt \& Whitney TALON X low emissions combustor: Revolutionary results with evolutionary technology. AIAA paper 20070386, Reno, NV, Jan 2007. DOI:10.2514/6.2007-386.

[19] Johnson MR, Littlejohn D, Nazeer WA, Smith KO, and Cheng RK. A comparison of the flowfields and emissions of high-swirl injectors and low-swirl injectors for lean pre- 
mixed gas turbines. Proceedings of the Combustion Institute, 30(2):2867 - 2874, 2005. DOI:/10.1016/j.proci.2004.07.040.

[20] Rizk NK and Mongia HC. Semi-analytical correlations for NOx, CO and UHC emissions. In ASME Gas Turbine Conference, Paper 92-GT-130, Cologne, Germany, June 1992. DOI:10.1115/92-GT-130.

[21] Tacina KM, Lee CM, and Wey C. NASA Glenn high pressure low NOx emissions research. Technical Report TM-2008-214974, NASA, Feb 2008.

[22] Cohen JD. Analytical fuel property effects - Small combustors. In Assessment of Alternative Aircraft Fuels, NASA CP-2307, page p. 93, Nov. 1983.

[23] Wey C, Anderson B, Wey C, Miake-Lye R, Whitefield R, and Howard R. Overview on the aircraft particle emissions experiment (APEX). J. Propulsion ES Power, 23(5):898-905, 2007. DOI:10.2514/1.26406.

[24] Filippone A. Advanced Aircraft Flight Performance. Cambridge Univ. Press, 2012.

[25] Filippone A. Multi-disciplinary simulation of propeller-turboprop aircraft flight. Aeronautical J., 116(1184):985-1014, Oct 2012. DOI:10.1017/S0001924000007454.

[26] Baughcum SL, Tritz TG, Henderson SC, and Pickett DC. Scheduled civil aircraft emission inventories for 1992: Database development and analysis. Technical Report NASA CR-4700, NASA, April 1996. Appendix D.

[27] Turgut E, Cavcar M, Usamaz O, Yay O, Dogeroglu T, and Armutlu K. Investigating actual landing and takeoff operations for time-in-mode, fuel and emissions parameters on domestic routes in Turkey. Transportation Research Part D, 53:249-262, 2017. DOI:10.1016/j.trd.2017.04.018. 


\section{A Correlation Data}

Table A1: Coefficients of Eq. 3 for turbofan emission model; $n=$ number of engines in database. Cut-off test-date: 1985.

\begin{tabular}{|c|c|c|c|c|c|c|c|c|}
\hline EI & $a$ & $b$ & $c$ & $d$ & $e$ & $f$ & $r$ & $n$ \\
\hline \multicolumn{9}{|c|}{ Takeoff } \\
\hline $\mathrm{NOx}$ & $-0.6026 e+2$ & $0.8782 e+0$ & $0.1293 e-1$ & $0.9680 e+1$ & $-0.3723 e+0$ & $-0.2644 e-1$ & 7.01713 & 395 \\
\hline $\mathrm{CO}$ & $-0.8542 e+1$ & $0.2230 e+0$ & $-0.1555 e-2$ & $0.1189 e+1$ & $-0.3791 e-1$ & $-0.1464 e-1$ & 0.25929 & 389 \\
\hline $\mathrm{HC}$ & $0.9451 e+0$ & $-0.2969 e-1$ & $0.1671 e-3$ & $-0.7388 e-1$ & $0.6899 e-3$ & $0.1710 e-2$ & 0.04930 & 388 \\
\hline $\mathrm{SN}$ & $-0.8321 e+2$ & $0.3256 e+1$ & $-0.3673 e-1$ & $0.7262 e+1$ & $-0.1391 e+0$ & $-0.1067 e+0$ & 3.99624 & 394 \\
\hline \multicolumn{9}{|c|}{ Climbout } \\
\hline NOx & $-0.1226 e+3$ & $0.3609 e+1$ & $-0.1684 e-1$ & $0.1958 e+2$ & $-0.7642 e+0$ & $-0.2313 e+0$ & 6.12832 & 396 \\
\hline $\mathrm{CO}$ & $-0.9324 e+1$ & $0.3059 e+0$ & $-0.2166 e-2$ & $0.1327 e+1$ & $-0.3697 e-1$ & $-0.2369 e-1$ & 0.37030 & 389 \\
\hline $\mathrm{HC}$ & $0.4873 e+0$ & $-0.2293 e-1$ & $0.1506 e-3$ & $0.3785 e-2$ & $-0.3222 e-2$ & $0.1253 e-2$ & 0.06129 & 389 \\
\hline SN & $-0.2677 e+2$ & $0.1093 e+1$ & $-0.1909 e-1$ & $0.2800 e+1$ & $-0.1496 e+0$ & $0.1695 e-1$ & 3.26990 & 392 \\
\hline \multicolumn{9}{|c|}{ Approach } \\
\hline NOx & $-0.3447 e+2$ & $0.1695 e+1$ & $-0.1384 e-1$ & $0.1320 e+2$ & $-0.1190 e+1$ & $-0.2531 e+0$ & 1.72064 & 398 \\
\hline $\mathrm{CO}$ & $0.2134 e+2$ & $-0.4416 e+0$ & $0.2066 e-2$ & $-0.8409 e+1$ & $0.1220 e+1$ & $0.8128 e-1$ & 1.81451 & 380 \\
\hline $\mathrm{HC}$ & $-0.1181 e+1$ & $0.6224 e-2$ & $0.3943 e-4$ & $0.9949 e+0$ & $-0.1501 e+0$ & $-0.5507 e-2$ & 0.35106 & 386 \\
\hline $\mathrm{SN}$ & $0.3220 e+1$ & $-0.6787 e-1$ & $0.1905 e-2$ & $-0.1231 e+1$ & $0.1470 e+0$ & $0.7839 e-2$ & 1.41086 & 389 \\
\hline \multicolumn{9}{|l|}{ Idle } \\
\hline $\mathrm{NOx}$ & $-0.9113 e+1$ & $0.4164 e+0$ & $-0.3209 e-2$ & $0.1120 e+2$ & $-0.3185 e+1$ & $-0.1285 e+0$ & 0.58958 & 394 \\
\hline $\mathrm{CO}$ & $-0.1286 e+3$ & $0.6372 e+1$ & $-0.6598 e-1$ & $0.1804 e+3$ & $-0.4570 e+2$ & $-0.3728 e+1$ & 10.40077 & 389 \\
\hline $\mathrm{HC}$ & $-0.1096 e+2$ & $0.8805 e+0$ & $-0.1033 e-1$ & $0.1808 e+2$ & $-0.4260 e+1$ & $-0.5871 e+0$ & 3.10105 & 389 \\
\hline SN & $0.9072 e+1$ & $-0.1836 e+0$ & $-0.4484 e-3$ & $-0.1138 e+2$ & $0.2659 e+1$ & $0.2239 e+0$ & 1.04649 & 389 \\
\hline
\end{tabular}


Table A2: Coefficients of Eq. 3 for turboprop/turboshaft emission model; $n=$ number of engines in database. Cut-off test-date: 1985.

\begin{tabular}{|c|c|c|c|c|c|c|c|c|}
\hline EI & $a$ & $b$ & $c$ & $d$ & $e$ & $f$ & $r$ & $n$ \\
\hline \multicolumn{9}{|c|}{ Takeoff } \\
\hline $\mathrm{NOx}$ & $0.1337 e+2$ & $0.9144 e-1$ & $0.3617 e-4$ & $-0.1075 e+1$ & $-0.6473 e+0$ & $0.2994 e+0$ & 6.04636 & 395 \\
\hline $\mathrm{CO}$ & $-0.4312 e+0$ & $0.9648 e-1$ & $-0.2328 e-2$ & $-0.5474 e+0$ & $-0.1131 e+0$ & $0.2726 e-1$ & 0.24908 & 389 \\
\hline $\mathrm{HC}$ & $0.1713 e+0$ & $-0.1004 e-1$ & $0.1902 e-3$ & $0.8724 e-1$ & $0.5984 e-2$ & $-0.3085 e-2$ & 0.05069 & 388 \\
\hline $\mathrm{SN}$ & $-0.7601 e+1$ & $0.1142 e+1$ & $-0.2213 e-1$ & $0.9802 e+0$ & $-0.1369 e+0$ & $-0.8636 e-2$ & 4.20621 & 394 \\
\hline \multicolumn{9}{|c|}{ Climbout } \\
\hline NOx & $0.7194 e+1$ & $0.5609 e+0$ & $-0.1059 e-1$ & $-0.3223 e+1$ & $0.2889 e+0$ & $0.2591 e+0$ & 5.25297 & 396 \\
\hline $\mathrm{CO}$ & $0.1788 e+0$ & $0.5469 e-1$ & $-0.1710 e-2$ & $-0.5147 e+0$ & $-0.2318 e+0$ & $0.3439 e-1$ & 0.36576 & 389 \\
\hline $\mathrm{HC}$ & $0.2859 e+0$ & $-0.1764 e-1$ & $0.3169 e-3$ & $0.1465 e+0$ & $0.9445 e-2$ & $-0.4966 e-2$ & 0.06137 & 389 \\
\hline $\mathrm{SN}$ & $-0.1914 e+2$ & $0.1839 e+1$ & $-0.3592 e-1$ & $-0.3807 e+1$ & $-0.1654 e+1$ & $0.2614 e+0$ & 3.27922 & 392 \\
\hline \multicolumn{9}{|c|}{ Approach } \\
\hline $\mathrm{NOx}$ & $0.3699 e+0$ & $0.5470 e+0$ & $-0.7445 e-2$ & $-0.6914 e+1$ & $0.6782 e+1$ & $0.1138 e+0$ & 1.53381 & 398 \\
\hline $\mathrm{CO}$ & $0.8187 e+1$ & $-0.2967 e+0$ & $0.5588 e-2$ & $0.3856 e+1$ & $0.4757 e+1$ & $-0.3191 e+0$ & 1.81015 & 380 \\
\hline $\mathrm{HC}$ & $0.5958 e+0$ & $-0.2780 e-1$ & $0.1839 e-3$ & $0.7055 e+0$ & $-0.6934 e+0$ & $0.6639 e-2$ & 0.34968 & 386 \\
\hline $\mathrm{SN}$ & $-0.7969 e+0$ & $0.1014 e+0$ & $-0.3505 e-2$ & $-0.1549 e+1$ & $-0.1322 e+2$ & $0.4516 e+0$ & 1.33569 & 389 \\
\hline \multicolumn{9}{|l|}{ Idle } \\
\hline $\mathrm{NOx}$ & $0.1605 e+0$ & $0.2412 e+0$ & $-0.1650 e-2$ & $-0.8818 e+1$ & $0.3714 e+2$ & $-0.2268 e+0$ & 0.58430 & 394 \\
\hline $\mathrm{CO}$ & $0.2051 e+2$ & $0.1776 e+1$ & $-0.4778 e-1$ & $-0.1390 e+3$ & $0.1528 e+3$ & $0.2915 e+1$ & 10.51605 & 389 \\
\hline $\mathrm{HC}$ & $0.4966 e+1$ & $-0.1452 e+0$ & $-0.1305 e-2$ & $0.3729 e+2$ & $-0.3787 e+2$ & $-0.2503 e+0$ & 3.11248 & 389 \\
\hline $\mathrm{SN}$ & $-0.1868 e+1$ & $0.1876 e+0$ & $-0.2811 e-2$ & $0.3949 e+1$ & $0.3192 e+0$ & $-0.1473 e+0$ & 1.04944 & 389 \\
\hline
\end{tabular}

